\section{A Violência Masculina é Dirigida para Eva ou Maria?}

\author{
Ceci Vilar Noronha* \\ Maria Esther Daltro**
}

"A ideologia machista incorpora dois arquétipos de ser mulher enquanto um ser para o homem: Eva, sedutora $e$ Maria, a mãe. A primeira para encantar o homem $e$ a segunda, para gerar os filhos do homem; ambas para servi-lo." (Azevedo, 1985, päg 127)
* Sociologa do Nacleo de Estudos Mulher e Salude, Departamento de Medicina Preventiva, Faculdade de Medicina UFBA. ** Médica do Nacleo de Estudos Mulher e Salde, Departamento de Medicina Preventiva, Faculdade de Medicina, UFBA.

Este trabalho analisa os diferenciais por gênero de mortes violentas e outras agressōes ocorridas na Bahia. No país, é crescente a importância dos agravos externos no conjunto das causas de bbito. Ademais, os atos violentos tendem a pressionar a demanda por atendimentos de emergência nos serviços de saúde. Os dados emplricos foram coligidos na imprensa escrita, cobrindo todos os homicidios, tentativas de homictdio e estupros noticiados em 1989. A violência policial despontou como responsável pela morte de uma alta proporção de jovens do sexo masculino. Em seguida, as desavenças entre indivtduos considerados marginais ou os assassinatos atribuidos $\dot{a}$ "queima-de-arquivo". Com relaçẫo às mulheres, a dimensão quantitativa dos crimes é menor, mais difusa e resultante das relaçōes familiares. Os estudos revisados apontam para a generalizaçâo do dominio masculino sobre a mulher na interpretação das reaçôes violentas. Fazer resistência à ideologia de gênero que inferioriza a mulher significa, simultaneamente, evitar agressões $e$ homicldios - uma tarefa complexa para a sociedade brasileira.

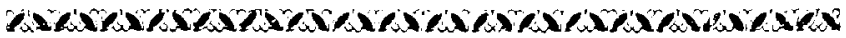

\section{INTRODUÇÃO}

A mais recente análise do quadro sanitário brasileiro aponta para o posicionamento, em terceiro lugar, dos agravos externos (violências, inclusive) entre as causas de 6bito, em 1984. As taxas de mortalidade por homicidio foram crescendo por todas as regiöes do país, no perfodo 1979/83, passando de 9,6 por Cadernos de Saúde Páblica, RJ, 7 (2): 215-231, abr/jun, 1991 
100 mil habitantes para 13,6 , no último ano considerado. Destaca-se, especificamente, o segmento dos adultos jovens do sexo masculino como as principais vítimas das agressōes e homicídios (Possas, 1989).

Ao longo do tempo a violência tem estado presente nas relações entre os homens, mas existem escassas investigaçōes empíricas que possibilitem apreender o fenômeno de forma mais abrangente. Ademais, algum nível de violência é exercitado com legitimação social, cujas margens de aceitabilidade são mutáveis no tempo. Apesar dos níveis de dificuldade apontados, os dados passíveis de serem coligidos, ainda que parciais, são úteis como parâmetros indicativos do fenômeno.

A violência é um tema que tem ocupado um espaço cada vez maior na mídia falada e escrita, na conversa entre os amigos, nas pesquisas do Ibope, nas plataformas dos polfticos nos sermōes dos religiosos, enfim, no cotidiano dos indivíduos da sociedade moderna.

O termo violência tem como eixo de significação a idéia de força, opressão que se impōe de um pólo sobre outro. E possível, também, distinguir um nível de violência perceptf́vel por sua ação destrutiva nos corpos, no ambiente e em objetos materiais. Outro plano da violência ocorre de modo pouco perceptível e de diffcil mensuração, porque atinge um universo simbólico dos individuos. Definir violência é uma tarefa complexa, basicamente porque a idéia é associada ao imprevisível, à ausência de norma, a um acontecimento sem regularidade ou estabilidade, onde tudo pode acontecer a qualquer momento. Sempre que se tenta enquadrar esse fenômeno nos limites de uma definição, dissimula-se a divergência e a heterogeneidade de cada grupo humano. Entretanto, juristas, antropólogos, sociólogos elaboraram conceitos de violência que variam na sua amplitude. Destaca-se uma conceituação que parece ser mais completa:

Há violência quando, numa situaçāo de interação, um ou vários atores agem de maneira direta ou indireta, maciça ou esparsa, causando danos a uma ou várias pessoas em graus variáveis, seja em sua integridade flsica, seja em sua integridade moral, em suas posses, ou em suas participaçōes simbolicas e culturais (Michaud, 1989, pág.9).

Atualmente, a maioria das consideraçōes sobre a violência se concentra na criminalidade. Pesquisas de opinião pública têm mostrado que a segurança passou ao primeiro plano na agenda das demandas das populaçōes metropolitanas, e a percepção generalizada É de que a situaçāo vem se agravando a cada dia. Uma pesquisa do Ibope, encomendada pela Polf́cia Militar do Estado do Rio de Janeiro, revelou que, para $78 \%$ da população da capital, o quadro de segurança 
pública teve uma "grande piora", durante os dois ultimos anos anteriores à entrevista. Para $62 \%$ dos entrevistados, a situação tende a piorar (Coelho, 1988).

A idéia da imprevisibilidade da violência é, também, relacionada à idéia de insegurança. O sentimento de insegurança, que se encontra nas rafzes das discussões sobre o aumento da violência, raramente repousa sobre a experiência direta da violência. Ele corresponde à crença, fundada ou não, de que tudo pode ancontecer, de que se deve esperar tudo $\mathrm{\rho u}$, ainda, de näo se poder mais ter certeza de nada. E reconhecido que os meios de comunicação de massa têm um papel destacado na geração de imagens que contribuem para as idéias e representações sociais acerca da violência, principalmente a violência urbana.

A violência, com a carga de ruptura que ela veicula, é por princtpio um alimento privilegiado para a midia, com a vantagem para as violências espetaculares, sangrentas ou atrozes sobre as violências comuns, banais e instaladas (Michaud, 1986 pág.49).

A crença no aumento contínuo da violência tem a midia como fonte alimentadora, a qual tende a ampliar o tempo e o espaço dedicados ao espetáculo da violência. A TV Globo fez, nos flltimos meses, os espectadores vivenciarem, ao vivo, todos os seqūestros realizados no Brasil. Tudo isso com uma estrutura organizacional espetacular, onde até foi criado um logotipo especifico para cada seqūestro.

Não raro um crime toma as primeiras páginas de imprensa escrita. Geralmente esses casos são acompanhados, durante algum tempo, de uma maneira novelesca, cheia de sensacionalismo, explorando ou a perversidade do caso, ou a posição de prestígio dos envolvidos. As denúncias do aumento da violência e da insegurança, hoje, tendem a assimilar qualquer desordem como uma violência que ameaça a ordem social como um todo. Um exemplo disso é o recente conflito do Kuwait, quando a idéia de uma terceira guerra mundial tomou conta quase que instantaneamente da imprensa. Năo somente a guerra, mas também os comportamentos criminosos sẫo percebidos com uma ansiedade por vezes desproporcional em relação ao seu volume real. Esta crescente insegurança sentida pela população modema está diretamente relacionada com as normas culturais de cada lugar. São estas normas que determinam o que será considerado como crime.

O surgimento do tema da violência nas preocupações da opinião páblica não é neutro: traduz avaliaçōes positivas ou negativas que são condicionadas por valores culturais da sociedade em questão. Assim, não há um saber universal sobre a violência: cada sociedade define e julga sua própria violência segundo seus pró-

Cadernos de Saude Páblica, RJ, 7 (2): 215-231, abr/jun, 1991 
prios critérios. Um exemplo desta definição cultural da violência ế a liberdade que a mulher tem de se locomover no espaço urbano. Em países árabes e alguns países da Amética Latina, dificilmente uma mulher sai, à noite, desacompanhada de alguém do sexo masculino sem ser molestada ou mesmo agredida fisicamente. Este tipo de incidente näo é considerado crime, sendo até mesmo estimulado pela sociedade. Entretanto, em alguns países do Norte da Europa, o mesmo fato acarretaria problemas sérios para o agressor. Outro exemplo muito comum, em algumas regióes do Brasil, é a heroificação do assassino que mata a companheira $e$, por conta da "defesa da honra", é absolvido através de um júri popular.

Em alguns países, a lei permite certas violências em condiçôes bem definidas, No Brasil, por exemplo, a polícia mata em proporções alarmantes, e é possível indagar quantos crimes estão encobertos nesta capa protetora de impunidade. $\mathrm{Na}$ Inglaterra, por exemplo, raramente $\varepsilon$ permitido ao policial carregar uma arma.

Historiadores da violência na Idade Média e na Revolução Industrial são unânimes em reconhecer a onipresença da violência nas relaçōes humanas. Langley e Levy (1980) descrevem que especificamente a violência contra a mulher, os castigos físicos, a flagelação e a tortura eram legitimadas pelos poderes civis e eclesiásticos. Somente a partir do século XIX é que as leis e os tribunais deixam de reconhecer o direito do marido de castigar as esposas e reconhecem o direito de castigar os maridos agressores. Para Michaud (1989), a partir do século XIX, houve uma "pacificação progressiva da sociedade". Não só no que diz respeito à mulher, mas de uma maneira geral a sociedade se civilizou. A partir desta época, com o crescente esquadrinhamento, a classificação dos indivíduos, o desaparecimento das multidōes sem identificação, houve uma diminuição da violência, às custas de uma restrição da vida social e da ascensão dos controles sociais.

Muito se tem escrito sobre as causas da violência e, mais especificamente, sobre a criminalidade. Há, basicamente, dois quadros teóricos para a interpretação desse complexo fenômeno. Um relacionado com a justiça retributiva, que demanda por mais efeitos policiais e de segurança para conter a violência. Outro vincula a criminalidade à pobreza, às carências, e à marginalização dos grupos desenraizados pelas transformaçōes agrárias (Coelho, 1988).

\section{METODOLOGIA}

A fonte de informações utilizada no levantamento empírico foi o jomal "A Tarde", periódico fundado 
em 1912, aquele que tem maior circulação no Norte e Nordeste e que dispōe de mais recursos humanos e equipamentos para a cobertura dos eventos estudados.

Das matérias publicadas sobre violência, em 1989, foram trabalhadas seis variáveis com relação à vítima (nome, sexo, idade, profissão, arma utilizada na agressão/homicídio, área geográfica, local da agressão ou homicídio). A variável motivo do crimelatentado caracteriza, também, o agressor. Cada matéria foi transcrita do jornal para um mapa contendo as variáveis selecionadas para o estudo. A partir deste mapa, construiu-se o banco de dados para processamento em microcomputador. Todos os casos de homicídio, tentativa de homicídio ou estupro publicados no jornal "A Tarde" foram computados.

Do material transcrito foram abandonados 28 casos, devido à existência de dúvidas quanto à causa de morte, se homicídio, suicídio ou acidente.

\section{A VIOLENNCIA NOTICIADA: DIFERENCIAIS POR GENERO}

Em 1989 foram noticiados, no jomal "A Tarde", 1.007 homicídios, 150 tentativas de homicídio e 25 estupros ocorridos no Estado da Bahia. Há uma tipologia para os atos violentos, na qual se destacam a violếncia policial $(23,9 \%)$; os crimes hediondos $(20,2 \%)$, os crimes por motivo fútil $(15,9 \%)$, a "queima-de-arquivo" $(12,5 \%)$, os crimes passionais $(8,7 \%)$, os crimes de mando $(8,3 \%)$ e outros $(6,4 \%)$ (Vide Gráfico I).

\section{GRÁFICO I}

Distribuição dos Atos Violentos Segundo o Motivo da Agressão no Estado da Bahia, 1989

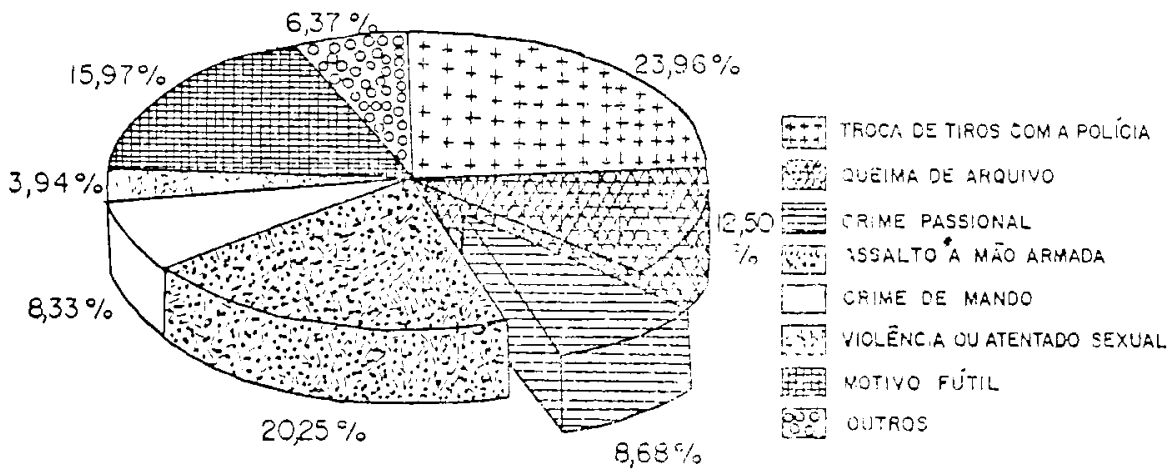


Em $87 \%$ dos casos, a vítima era do sexo masculino, sendo sobretudo jovem ( $40 \%$ ), entre 18 e 25 anos. Somando-se a essa proporção aquela dos menores de 18 anos $(13 \%)$, tem-se que $53 \%$ das vitimas foram agredidas ou assassinadas antes de atingir 26 anos.

Importa destacar que $46 \%$ das vítimas foram identificadas como assaltante, traficante ou marginal, correspondendo às caracteristicas anteriores de serem do sexo masculino e jovens. Os agressores que mais se destacam são os agentes policiais (242 casos, $24 \%$ ). Em segundo lugar, os marginais $(18,6 \%)$. Analisando os casos masculinos como um todo, os agressores que mais se destacam, em frequêencia, são os amigos ou conhecido da vitimas.

Condizente com essa violência predominantemente masculina, tanto na condição de vítima como de agressor, as armas de fogo, em sua grande variedade, constituem o instrumental mais utilizado $(68 \%)$, seguindo-se as armas brancas $(19 \%) e$, por último, outros instrumentos menos convencionais (pedra, pau, barra de ferro, foice, picareta, chuço etc), numa proporção de $13 \%$.

A troca de tiros entre policiais e marginais foi responsável por $24 \%$ (207) dos homicídios ou tentativas. Também se destacou como motivo do crime, atingindo a proporção de 12,5\% (108), a "queima-dearquivo" ou desavença na partilha de objetos roubados, que resulta da disputa entre aqueles que sobrevivem fora da lei, compreendendo desde os conflitos individuais até os conflitos entre quadrilhas organizadas.

Assim, a violência policial faz vítimas diárias entre o segmento identificado como marginal. Os marginais, por sua vez, disputam entre si, gerando mais violências e mortes. São crimes que ocorrem, principalmente, entre as camadas populares de Regiaao Metropolitana de Salvador, com destaque para Salvador e Camaçari. Na capital, os eventos estudados se localizam, sobretudo, no subúrbio ferroviário (uma extensa área pobre que compreende várias localidades como Lobato, Coutos, Paripe e Periperi) e outros bairros populares como Massaranduba, Uruguai, Pernambués, Beiru, Liberdade etc. Mesmo dentro das áreas populares, as notícias salientam a ocorrência dos crimes nas "zonas de invasão", enfatizando a associação entre pobreza e violência. No interior do estado, destacam-se as cidades de Itabuna, Feira de Santana e Vitória da Conquista.

Entre os tipos de crime que atingem mais diretamente homens, jovens e marginais, há os linchamentos realizados pela população. Foram noticiados 30 , no período de 12 meses; em alguns casos, as vítimas foram retiradas das delegacias para serem executadas. 
Alguns desses crimes foram mais elaborados do que a reação instintiva de uma multidão. Grupos organizados de taxistas, como uma força paramilitar, invadiram uma delegacia do interior do estado e seqũestraram um individuo que tinha se recusado a pagar o valor total de uma corrida de táxi, pertencente a um dos integrantes do grupo. Os taxistas mataram-no, mais tarde, em local deserto. ("A Tarde", 14/12/89).

Esse mesmo grupo já havia assassinado um marginal, como vingança por ele ter matado um taxista. Entende-se que a organização deste grupo deve ter sido fortemente influenciada pela alta exposição ao risco que esta categoria profissional apresenta. Durante o ano de $1989,21(1,7 \%)$ taxistas foram vítimas de agressōes. Esse número é extremamante alto, quando comparado ao de policiais, 35 casos $(4,4 \%)$ ou vigilantes, 29 casos $(3,7 \%)$, que desenvolvem funçōes mais diretamente expostas ao risco. Surpreendentemente, mais alto ainda é o risco a que estáo expostos os lavradores, atingido esta categoria a percentagem de $4,1 \%$ entre todos o crimes praticados (50 casos). Entretanto, diferente das categorias ocupacionais citadas acima, este grupo sofre agressão basicamente por dois motivos: questốes de terra $(30 \%)$ e motivos fúteis $(70 \%)$.

A chamada criminalidade violenta (crime hediondo), envolvendo elementos reconhecidos socialmente como marginais (os agressores) e a população (as vítimas), desponta numa proporção de $20 \%$ (175), dentre os eventos analisados. Nesse tipo de violência, a vítima e o agressor são, principalmente, do sexo masculino. Os vigilantes são os que mais perdem a vida devido a esse tipo de crime; 29 casos ocorrem, totalizando a percentagem de $16,6 \%$ entre todos os crimes hediondos; o que não é uma surpresa, se considerar que esses profissionais são treinados somente por duas semanas antes de receberem uma arma e assumirem o posto. Em seguida a categoria que está exposta ao risco desse tipo de agressão é a dos donos de pequenas empresas comerciais.

Outro tipo de violência na qual os homens se envolvem mais freqüentemente ficou evidenciado como crime por motivo fútil, que participa com $16 \%$ (138) do conjunto de atos analisados. Nestes casos, a vítima e o agressor são amigos, conhecidos ou vizinhos. $\mathrm{Na}$ maioria das vezes sẩo crimes não-premeditados que ocorrem a partir de uma discussão por qualquer motivo, seguindo-se a luta corporal e a agressão final. $O$ uso de bebidas alcoólicas é um fato recorrente nesses eventos. Esse tipo de crime também é descrito como decorrência de rivalidade, ou rixa, entre a vítima e o agressor, que se manifesta em diferentes oportunidades, indo num crescendo até o homicídio ou tentativa. Esses 
crimes, geralmente, ocorrem em locais páblicos como bares, clubes, festas populares etc. Um caso que demonstra bem a ideologia masculina por trás desse tipo de agressão ocorreu em uma cidade do interior, onde, em plena praça pública, dois rivais "duelaram", atingindo dois observantes, além de se matarem ("A Tarde", 17/6/89).

A participação da mulher na criminalidade é reconhecidamente menor, embora existam casos de mulheres assassinadas em cercos policiais ou por marginais; isso se deve, frequientemente, ao fato de ser a vitima companheira, mãe ou filha de um homem considerado fora-da-lei. Outras mulheres são ameaçadas por seu envolvimento afetivo com homens infratores.

No perfodo estudado, foi noticiada a existência de uma quadrilha chefiada por uma mulher que realizava assaltos a prédios de luxo. Quando a polícia conseguiu prendê-la, verificou-se que ela dividia a liderança do grupo com o marido. Foi insignificante, também, o número de vítimas femininas e cuja história de vida existisse o envolvimento com tráfico de drogas ou que tivessem executado crimes profissionalmente.

O evolvimento da mulher nos atos violentos analisados está centralizado nos denominados crimes passionais, na condição de vítima ou agressor, e nos casos de estupro.

Em 1989 foram noticiados 75 crimes passionais (inclusive tentativas de homicidio, sempre em menor número), que correspondem a $9 \%$ do total dos agravos externos em análise. Em 51 dos crimes passionais, o agressor era do sexo masculino (companheiro, ex- companheiro, noivo ou namorado).

Do noticiário local, os diferenciais por sexo mais importantes foram com relação a idade, local da agressão e arma utilizada. A mulher experimenta a violểncia em idades mais precoces do que o homem; isso se deve às uniōes conjugais entre jovens menores de 18 anos, freqëntes entre as camadas populares, e aos estupros a crianças. Foram estatisticamente significantes as diferenças de idade entre as vítimas (X2 $=52,44$ $\mathrm{p}<0,01$, Gráfico II).

As agressões à mulher ocorrem, sobretudo, em seu próprio lar. O espaço doméstico, tido como local de conforto, bem-estar e de proteção à mulher, é, na realidade, um espaço perigoso, à medida que é nele que $60 \%$ das vítimas do sexo feminino foram agredidas. Isto coloca em evidência o caráter violento das relaçōes familiares, onde a dominação e a resistência abrem caminho para o abuso fĺsico, psicológico e sexual. Independentemente de ter aumentado a participação da mulher na força de trabalho, as mulheres se expöem mais à morte violenta sem sair de casa, enquanto que os homens foram mais agredidos em 
locais públicos ou locais desertos, sendo esta diferença estatisticamente significante $(X 2=119,99 p<0,01$, Gráfico III).

\section{GRÁFICO II}

Distribuição dos Atos Violentos por Faixa Etária e Sexo da Vítima no Estado da Bahia, 1989

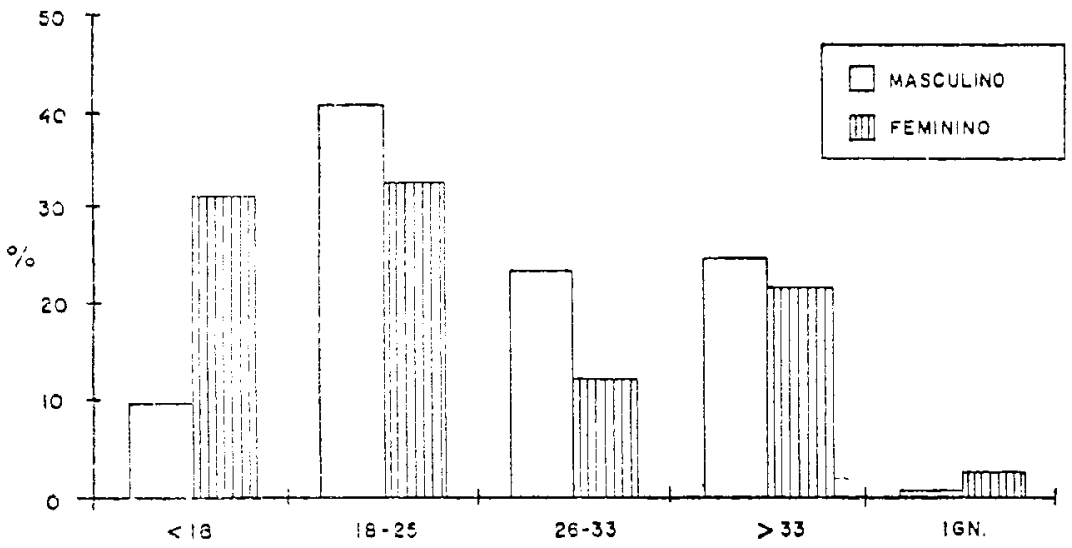

\section{GRÁFICO III}

Distribuição dos Atos Violentos por Local da Agressão e Sexo da Vítima no Estado da Bahia, 1989

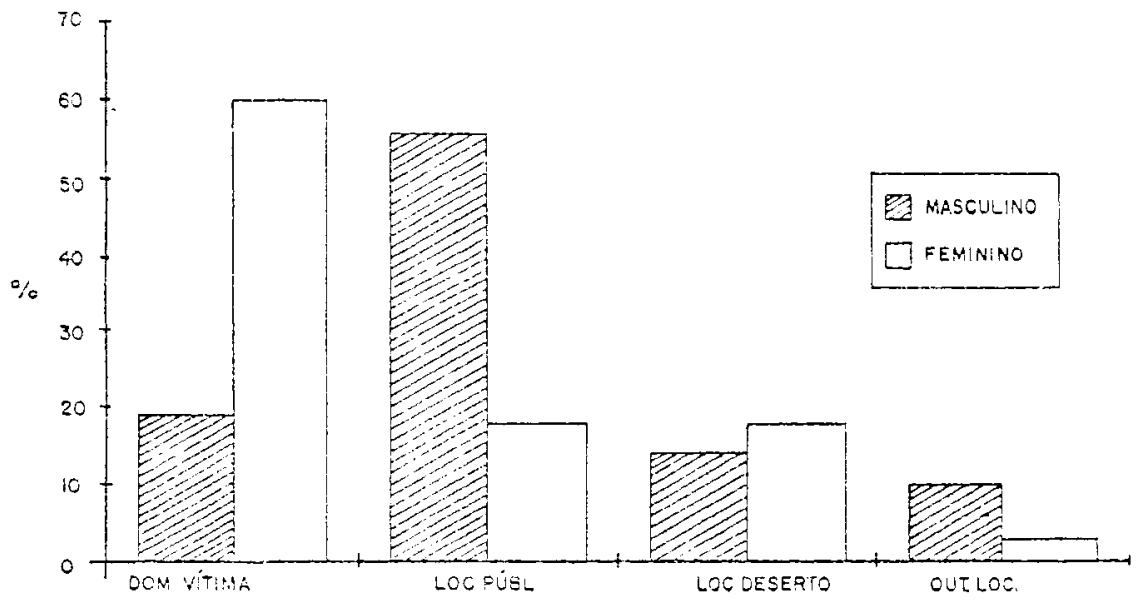


As mulheres também lutam no espaço doméstico (19 casos, 1,9\%), só que com menor eficácia do que os homens. Por vezes, a agressão, resulta em tentativa de homicídio.

Diferem, também, os meios de agressão utilizados nas vítimas do sexo masculino e feminino. As diferenças foram estatisticamente significantes (X2 $=41,19$ $\mathrm{p}<0,01)$, sugerindo que entre as mulheres é maior o número de crimes por meio de arma branca (faca, facāo, peixeira, punhal etc) ou outros instrumentos $(55 \%)$. As vítimas masculinas são assassinadas ou agredidas por armas de fogo, principalmente (Quadro I).

\section{QUADRO I}

Distribuição do Atos Violentos por Arma Utilizada na Agressão e Sexo da Vítima, no Estado da Bahia, 1989

\begin{tabular}{|c|c|c|c|c|c|c|c|c|}
\hline \multirow{3}{*}{$s \varepsilon \times 0$} & \multicolumn{6}{|c|}{ ARMA OA AGRESSÃO } & \multirow{2}{*}{\multicolumn{2}{|c|}{ TOTAL }} \\
\hline & \multicolumn{2}{|c|}{ AQMA DE FOGO } & \multicolumn{2}{|c|}{ ARMA BRANCA } & \multicolumn{2}{|c|}{ OUTRAS } & & \\
\hline & $N:$ & $\%$ & $N:$ & $\%$ & $\mathrm{~N}:$ & $\%$ & N: & $\%$ \\
\hline MASCULINO & 724 & 70,8 & 176 & 17,2 & 122 & 11,9 & 1022 & 100,0 \\
\hline FEMININO & 58 & 43,3 & 40 & 34,3 & 30 & 22,4 & 134 & 100,0 \\
\hline
\end{tabular}

Em relaçāo à violência que atinge preferencialmente a mulher, não existem diferenças quanto à sua distribuição geográfica: Região Metropolitana de Salvador (RMS) ou interior do estado. Isso parece in dicar que não há associação entre um maior ou menor grau de urbanização da área e os eventos violentos em análise, quando se trata de violência contra a mulher (Quadro $\Pi$ )

Os estupros representaram $16 \%$ das agressōes à mulher e chamam a atenção por envolverem meninas, mais freqüentemente na condição de vítimas de familiares (pai adotivo com destaque), entre os agressores. 


\section{QUADRO II}

Distribuição dos Atos Violentos por Área Geográfica

e Sexo da Vítima, no Estado da Bahia, 1989

\begin{tabular}{|c|c|c|c|c|c|c|}
\hline \multirow{3}{*}{$S E \times O$} & \multicolumn{4}{|c|}{$A^{\prime} R E A$} & \multirow{2}{*}{\multicolumn{2}{|c|}{ TOTAL }} \\
\hline & \multicolumn{2}{|c|}{ R.M.S } & \multicolumn{2}{|c|}{$\begin{array}{l}\text { INTERIOR } \\
\text { DO ESTADO }\end{array}$} & & \\
\hline & $\mathrm{N}:$ & $\%$ & N: & $\%$ & $\mathrm{~N}:$ & $\%$ \\
\hline MASCULINO & 681 & 65,0 & 366 & 35,0 & 1047 & 100,0 \\
\hline FEMININO & 95 & 61,3 & 60 & 38,7 & 155 & 100,0 \\
\hline
\end{tabular}

$\left(x^{2}=0,67506 ; p>0,05\right)$

\section{A VIOLÊNCIA CONTRA A MULHER EM CARTAZ}

Com relação ao estupro, os dados quantitativos apresentados (25) deixam perceber muito pouco a dimensāo real da sua ocorrência. Como já foi discutido nesse trabalho, nenhuma forma de coleta de dados desta natureza é completa. Este fato fica mais pronunciado, quando se trata de crime de estupro. Nem todas as mulheres atingidas submetem-se ao constrangimento de procurar a polícia, graças às implicaçōes sociais que este tipo de criminalidade acarreta. Os casos noticiados são todos de vítimas pertencentes ao baixo estrato social, devido a razōes óbvias. Sabe-se, entretanto, que eles podem ocorrer em outras camadas sociais.

Um fato que comprova o alto indice de violência sexual é o de que, quando se noticia a prisão de um estuprador, $\&$ freqüente destacar-se a possibilidade do autor ser responsável por vários outros atos semelhantes.

$O$ "perigoso estuprador" $R . L$. de J., acusado de vários estupros nas áreas do Beiru e Pernambués (bairros populares de Salvador), foi preso por um acaso quando se envolveu numa briga da rua ("A Tarde", 14/06/89).

Foi preso o vendedor ambulante C.J. de A., 30 anos, natural do interior de Pernambuco, acusa- 
do de mais de 30 estupros na cidade de Senhor do Bonfim. Ele costumava atacar mulheres casadas, durante a noite, na casa das vitimas ou na rua. Ameaçava as mulheres de morte se o denunciassem (A Tarde, 14/06/89).

Foi preso $A . R ., 46$ anos, lavrador, por ter estuprado sua filha de 20 anos e tentado violentar as outras quatro filhas, todas menores de idade. A filha mais velha está grávida de 3 meses. Fato de Guareju (Vitoria da Conquista) (A Tarde, 02/08/89).

J.S.B., 45 anos, pai-de-santo, foi acusado de ter estuprado a menor $K . S$. , de 8 anos, transmitindo à mesma uma doença venérea. A mãe da criança é filha-de-santo do acusado e ficou revoltada com o fato, denunciando-o d̀ polfcia. A responsável pela criança é viúva e acredita que este não seja um fato isolado. Outras menores podem ter sido vitimas do pai-de-santo "A Tarde", $07 / 12 / 89)$.

G.S. Lima, C.C. e N.S.S. morreram numa troca de tiros com a polfcia numa ação conjunta das polícias Civil e Militar, em Ilhéus. Os criminosos assassinados eram responsáveis por 13 estupros (se supöe que até mais) $e$ alguns furtos ("A Tarde", 19/02/89).

\section{A MULHER COMO AGRESSORA}

Geralmente os crimes passionais têm uma história em que, primeiro, há conflitos, cenas, queixas, lesỏes corporais, por vezes, até o ato mais grave se consumar. $V . F . F ., 27$ anos, lavrador, morto por sua companheira também lavradora, de 24 anos, por ciúmes. O marido não mantinha relaçóes sexuais com ela hâ algum tempo. Ela premeditou tudo, esperou o marido dormir, despertando-o mais tarde com agua fervendo e o feriu com facâo(" $\mathrm{A}$ Tarde", 10/01/89).

J.C. da S., 40 anos, vaqueiro, morador da zona rural do munictpio de Irecê, foi morto por sua mulher, sogra, cunhado e o amante da esposa. Todos trabalhadores rurais. $O$ casal teve 10 filhos ("A Tarde", 22/04/89).

C.A. de A. Santos, 24 anos, vendedor ambulante, assassinado por arma de fogo, em sua residência no bairro Nordeste de Amaralina. A agressora foi sua ex-companheira, que voltou à casa onde 
viviam juntos, acompanhada de um irmão que é soldado, para pegar as suas coisas. O casal discutiu nessa ocasiâo e a ex-companheira atirou, fugindo após o crime ("A Tarde", $23 / 04 / 89$ ).

$J$. dos J., 43 anos, lavrador, assassinado a pauladas pela esposa que em seguida enterrou o cadáver no quintal da casa, numa fazenda no municipio de Alagoinhas. A homicida se defendeu falando que era espancada diariamente pelo companheiro, a ponto de, em 8 anos de união conjugal, não ter tido filhos, uma vez que era espancada e perdia a criança. O marido tinha uma amante ("A Tarde", 16709/89).

A.O. de J., 28 anos, magarefe, assassinado por sua companheira J.C.M., 15 anos, no interior da residência de ambos, em Feira de Santana. A vitima morava na casa de sua companheira $e$ da avo desta. O crime aconteceu porque A.O. de J. surrou a anciä e J.C.M. a defendeu com uma faca. Eram constantes as ameaças de pancadas feitas pela vítima e a jovem acabava sempre apanhando. No mesmo dia do crime J.C.M. foi assassinada a tiros pelo cunhado, para vingar a morte do irmäo ("A Tarde", 30/11/89).

\section{QUADRO INTERPRETATIVO DA VIOLÊNCIA} CONTRA A MULHER

Uma interpretação mais genérica para a violência que toma a mulher como alvo relaciona os atos violentos à condição de inferioridade que o sexo feminino ocupa na sociedade. Esta condição $\varepsilon$ socialmente constitửda via geração de idéias, valores e crenças que legitimam um padräo de relacionamento assimétrico entre os homens $e$ as mulheres. A ideologia de gênero tem como racionalidade propria a superioridade masculina que, ao ser afirmada, reafirma, simultaneamente, a inferioridade feminina (Azevedo, 1985).

Cumpre destacar que a ideologia de gênero é, em si, uma forma de violência simbólica do homem contra a mulher. Atua como uma força dificilmente perceptível, que leva o pólo dominado a suportar a opressão e até mesmo considerá-la como natural e necessária para manter a ordem das coisas. A violência fisica se faz necessária para manter a hierarquização entre os sexos, quando o pólo subjugado contesta com maior veemência a ordem desigual.

De modo mais global, Azevedo (1985) distingue como fatores "explicativos" da violência nas relaçōes familiares a opressāo da ordem social, econômica e Cadernos de Saúde Pública, RJ, 7 (2): 215-231, abr/jun, 1991 
política que atinge a todos que vivem em sociedades estruturadas a partir dos antagonismos de classes. A identidade social da mulher, elaborada de modo a inferiorizá-la, com a participaçāo de várias - senăo todas - instituiçōes sociais. A ideologia machista, que visa preservar o mito da superioridade masculina. E as representaçōes das relaçōes de gênero no âmbito de determinadas famflias, que permitem aflorar a violência fisica.

Goldenberg e colaboradoras (1989), nessa mesma linha interpretativa, ressaltam que, no âmbito público, a dominaçáo do homem sobre a mulher se faz de forma velada, devido aos antagonismos de classes. No espaço doméstico atenua-se a dominação de classe, e a mulher toma-se depositária, por mecanismos de transferência realizados pelo homem, dos conflitos vividos na esfera pública.

No modo de produção capitalista, houve algum avanço na direção de uma sociedade igualitária apenas no plano jurídico. A simetria nas relaçōes entre os sexos ainda está por ser construída, apesar da maior participação feminina na força de trabalho, nos nfveis de educação formal, na vida política etc.

A importância social atribuída à mulher, ainda hoje, provém da sua funçāo de reprodutora da espécie, cuja função se articula com a necessidade capitalista de reprodução da força de trabalho. Vale a ressalva de que o capital monopolista, no Terceiro Mundo, tomou-se mais exigente quanto à quantidade e à qualidade da força de trabalho necessarias à produção.

No entanto, a historicidade da construção da identidade feminina como um ser inferiorizado desloca a discussão para a constituição e manutenção da família patriarcal que precede ao modo de produção capita. lista.

São conhecidos os nexos entre o poder do pai de famflia e a subordinação da esposa e filhos no sistema patriarcal (Engels, 1974).

Estudos antropológicos vêm apontando que a dominação da mulher pelo homem é universal e resulta do controle que os homens impuseram sobre a função reprodutiva da mulher.

Godelier (1980) ressalta o fato de que as contradiçōes entre os sexos são anteriores à consolidação do modo de produção capitalista $\mathrm{e}$, portanto, anteriores às contradiçōes entre as classes sociais. Buscando historicamente os fundamentos destas contradiçōes, o autor reporta que, em todas as sociedades, as mulheres sem filhos, seja por questōes de esterilidade ou não, desfrutam um status especial, inferior ou superior ao 
das mulheres fêrteis, mas notadamente um status diferenciado. Salienta, portanto, que os homens buscam - controle, sobretudo, das funçōes reprodutoras da mulher:

Os homens que dominam o processo de produção material e que possuem o monopólio dos complexos saberes da caça e da violência armada controlam as mulheres não como produtoras, mas como reprodutoras da vida que prolonga o grupo (Godelier, 1980, pag.22).

Desta forma, a capacidade reprodutiva da mulher transforma-se no lastro da sua submissão ao homem, ao mesmo tempo que ameaça a ordem masculina. $O$ homem tende a exercer uma vigilância constante que gera conflitos e violências.

Uma questão básica permanece, desafiando os estudiosos e o movimento feminista, a qual, com diferentes formulaçōes, contém a perplexidade pela condição generalizada da opressão à mulher. Uma opressão que guarda especificidades com relação a outros tipos de opressāo.

Argumentos que atenuem, em parte, essa perplexidade são buscados nos estudos antropológicos. No entanto, os materiais etnográficos sobre as sociedades de pequena escala confirmavam a universidade da hierarquia sexual, inclusive nos sistemas de parentesco matrilineares. O matriarcado como única exceção terminou por confirmar a regra, não passando de uma construção mítica, ao idealizar uma sociedade que seria o reverso das sociedades conhecidas.

As mulheres amamentam e parem os filhos e isso tem conseqüências importantes na vida social. Os sexos diferem quanto aos órgãos reprodutivos, hormônios e, talvez, em resistência física. Mas tais diferenças dizem pouco sobre a identidade social da mulher (Rosaldo, 1979).

Ortner (1979) enfatiza que tudo começa com o corpo e a função da procriação da mulher. Ou seja, - corpo feminino parece destinado à reprodução da vida; o homem, por estar praticamente liberado dessas tarefas, é impulsionado a criar " artificialmente" símbolos e tecnologias. Em muitas sociedades tradicionais é difficil perceber a mulher como geradora de cultura, e sua função de reprodutora a aproxima mais da natureza do que da ordem cultural.

Os valores culturais acerca das mulheres estão sempre relacionados ao seu estágio no ciclo da vida: menstruação, fertilidade, gestação e menopausa. A tese central da autora é que: a mulher está sendo identificada com - ou, se desejar, parece ser um simbolo - alguma coisa que cada cultura desvaloriza, alguma

Cadernos de Sade Pública, RJ, 7 (2): 215-231, abr/jun, 1991 
coisa que cada cultura determina como sendo uma ordem de existência inferior a si propria (Ortner, 1979, pág 100).

Vê-se que não há nenhum esquema interpretativo simples acerca da mulher e sua inserção na produção material da vida coletiva.

\section{CONSIDERAÇŌES FINAIS}

Hă uma vinculação entre violência e injustiça social. No estudo, os principais tipos de agressão pōem em relevo a existência de conflitos que estão não apenas entre o agressor e a vítima, mas nas relações sociais. Uma trama urdida por todos.

Com relação ao sexo masculino, a violência do Estado, via aparato policial, foi a tônica. Abater marginais é fato comum, diário e legítimo numa sociedade marcada pelas desigualdades. $\mathrm{Na}$ Bahia, ou no país, a cidadania é restrita a poucos indivíduos.

Quanto à mulher, a violência que se dirige contra ela emerge das relaçōes familiares. Outros estudos também referem uma freqüência acentuada do envolvimento de cônjuges em agressões físicas e homicídios (Azevedo, 1985; Goldenberg, 1989; Feiguin \& Bordini, 1987; Michaud, 1989).

A generalização dos padrōes de relaçōes opressivas sobre o sexo feminino ficou evidenciada nos seguintes termos: a criminalidade tende a se concentrar nas áreas mais urbanizadas (Regiảo Metropolitana de Salvador), enquanto que as agressōes e mortes que vitimizam as mulheres não apresentam tal característica.

Superar a assimetria nas relações que regem os papéis masculino e feminino é algo desafiante. Contém, de certo modo, a questão do grau de participação das mulheres na sua própria vitimização.

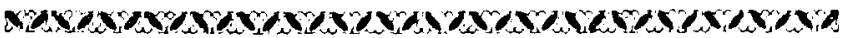

This paper analyses the different categories of violent death and other injuries occurred in Bahia. In Brazil, traffic acidents, homicides and suicides correspond to the third most common cause of death. Besides, violent acts tend to increase the emergency health services demand. The data were collected from the written press covering all the homicides, grave injuries and notified rapes during 1989. Police violence appeared as responsible for the death of a high proportion (24\%) of young males, followed by the disagreement between criminals $(18.6 \%)$. In relation to females, the quantitative dimension of crimes are lower, more diffused and registered in the family environment. The 
data point to the importance of male domination in the interpretation of those domestic violent acts. Resisting the ideology of women's inferiority means avoiding both injuries and homicides - a complex task for Brazilian society.

\section{AGRADECIMENTOS}

Muitos agradecimentos são dirigidos ao pessoal do setor de arquivo do jornal "A Tarde", pelo acesso aos jornais diários arquivados. As consultas ao arquivo foram imprescindfveis à coleta de dados para todos os dias do ano de 1989. Outros agradecimentos são devidos ao colega Carlos Maurício Cardeal Mendes, pela significativa ajuda na formação do arquivo e análise dos dados empíricos, via programa de microcomputadores.

\section{REFERÊNCIAS BIBLIOGRÁFICAS}

AZEVEDO, M.A. Mulheres espancadas: a violencia denunciada, Săo Paulo, Cortez, 1985.

BORDINI, E.B.T. \& FEIGUIN, D. Reflexőes sobre a violência contra a mulher. Rev. Sâo Paulo em Perspectiva, 1(2): 39-44, 1987.

COELHO, E.C. A criminalidade urbana violenta, Dados 31(2): 145-184, 1988.

ENGELS, F. A Origem da Famllia, da Propriedade Privada $e$ do Estado. Såo Paulo, Săo Paulo Editora, 1974.

FRANCHETTO, B.; CAVALCANTI. M.L.V. \& HEILBON, M.L. Antropologia e feminismo. Perspectiva Antropologica da Mulher (1): 11-47, Rio de Janeiro, Zahar, 1981.

GODELIER, M. As relaçőes homem/mulher e o problema da dominaçăo masculina Encontros com a Cìvilizaçäo Brasileira, 26: (9-29), Rio de Janeiro, Civilizaçăo Brasileira, 1980.

GOLDENBERG, P.; MEDRADO, M.P. \& PATERNOSTRO, M.A.N. A violência contra a mulher: uma questâo de saúde. In: LABRA, M.E. (org.) Mulher, salde e sociedade no Brasil, Petropolis, Vozes, 1989.

LANGLEY, R. \& LEVY, R.C. Mulheres espancadas - fenómeno invistvel, Såo Paulo, Hucitec, 1980.

MICHAUD, Y. A Violéncia, Săo Paulo, Ática, 1989.

ORTNER, S.B. Estr a muther para o homem assim como a natureza para a cultura? In: ROSALDO, M.Z. \& LAMPHERE, L. (coord). A mulher, a cultura e a sociedade, Rio de Janeiro, Paz e Terra, 1979.

POSSAS, C. Epidemiologia e Sociedade: heterogeneidade estrutural e saude no Brasil, Såo Paulo, Hucitec, 1989.

ROSALDO, M.Z. A mulher, a cultura e a sociedade: uma revisăo teórica, In - - \& LAMPHERE, L. (coord.) A mulher, a cultura e a sociedade, Rio de Janeiro, Paz e Terra, 1979. 